\title{
Effect of Ozonated Water Supplied Intermittently to Underground Roots on the Growth of Komatsuna (Brassica rapa var. perviridis)
}

\author{
Hideyuki Saito ${ }^{1} \&$ Satoru lizuka ${ }^{2, *}$ \\ ${ }^{1}$ School of Food, Agricultural and Environmental Sciences, Miyagi University, 2-2-1 Hatadate, \\ Taihaku, Sendai, Miyagi 982-0215, Japan; ${ }^{2}$ Department of Electrical Engineering, Graduate \\ School of Engineering, Tohoku University, 6-6-05 Aza Aoba, Aramaki, Aoba, Sendai, Miyagi 980- \\ 8579, Japan \\ *Address all correspondence to: Satoru Iizuka, Department of Electrical Engineering, Graduate School of Engineering, \\ Tohoku University, Aza Aoba 6-6-05, Aramaki, Aoba, Sendai, Miyagi 980-8579, Japan; Tel.: +81-22-795-7113; Fax: \\ +81-22-263-9374; iizuka@ecei.tohoku.ac.jp
}

\begin{abstract}
The effect of ozonated water on plant growth was examined. Ozonated water, produced by an atmospheric barrier discharge, was supplied intermittently twice a day, except on rainy and cloudy days, to the underground roots of komatsuna (Brassica rapa var. perviridis) by changing the feeding time interval. Being apart from the feeding position, the weights of komatsuna increased by 2.4 times in the case of 5 -sec feeding and 2.9 times in the cases of 78-sec feeding, compared to those of control. Intermittent supply of a suitable amount of ozonated water to the underground roots was found to activate plant growth.
\end{abstract}

KEY WORDS: barrier discharge, plant hormone, plant growth promotion

\section{INTRODUCTION}

Ozone is the most damaging air pollutant to plants. Ground level ozone causes more damage to plants than all other air pollutants combined. Ozone enters leaves through stomata during normal gas exchange. As a strong oxidant, ozone causes several types of symptoms, including chlorosis and necrosis. ${ }^{1-3}$

On the other hand, several studies have reported the effects of elevated $\mathrm{CO}_{2}$ and ozone on photosynthesis and growth. For example, soybeans grown at different combinations of $\mathrm{CO}_{2}$ and ozone showed that the negative effects of ozone on carbon assimilation were ameliorated and rates of photosynthesis were enhanced. ${ }^{4,5}$

It was also clarified that $\mathrm{CO}_{2}$ enrichment enhanced seed yield by $20 \%$ at ambient ozone, while it increased seed yield by $74 \%$ at twice the ambient ozone concentration. ${ }^{6}$ Thus, the negative effects of elevated ozone concentration on photosynthetic rate and seed production were ameliorated by elevated $\mathrm{CO}_{2}$. It is clear from these studies that the negative effects of ozone pollution on plant photosynthesis, growth, and yield were suppressed in the presence of elevated $\mathrm{CO}_{2}{ }^{.-9}$

Plants grown in elevated atmospheric ozone are known to undergo several biochemical changes before any damage can be detected. These reactions include increases in 
the activities of enzymes associated with general plant defense mechanisms. ${ }^{10,11}$ Ozone exposure often causes a surge in the production of the plant hormone ethylene, as well as changes in polyamine metabolism and increased activities of several enzymes in the phenylpropanoid and flavonoid pathways. The activities of superoxide dismutase and peroxidases that protect cells from the oxidative damage caused by hydroxyl radicals, $\mathrm{H}_{2} \mathrm{O}_{2}$, and superoxides also increase. ${ }^{12-14}$ Acute ozone exposure induces massive changes in gene expression, enzyme activities, and metabolic profiles even when no tissue damage is detected. ${ }^{15-18}$ The changes in protein activities (and gene expression) can occur very fast, within minutes after the onset of exposure. A common element in ozone and pathogen responses is active production of reactive oxygen species (ROS) in the apoplast. The signaling pathways activated by ozone are integrated into a complex regulatory system involving ROS, plant stress hormones, and second messengers such as calcium. ${ }^{11}$

The object of our experiments is to clarify the effect of ozone on plant growth. As described earlier, ozone causes several biochemical changes before any damage can be detected. These phenomena are closely related to plant defense mechanisms, increasing the surge production of the plant hormone ethylene and so on. In this way, plant responses to the ozone exposure occur on at least two timescales. One is a rapid defensive response in which plant hormones are secreted. Plants are internally activated by this response. The other is the relatively slow response to the oxidative damage caused by hydroxyl radicals, $\mathrm{H}_{2} \mathrm{O}_{2}$, and superoxides oxidization, causing several types of symptoms including chlorosis and necrosis.

Here, it is considered that the latter response can be prevented by shortening the exposure time to the ambient ozone, controlled by switching off the ozone generator intermittently in the experiment. If the latter response is prevented, then it is expected that the activated plant will produce a surge of the plant hormone ethylene, which will enhance its growth.

\section{EXPERIMENTAL APPARATUS AND METHOD}

The object of this study is to investigate the effect of ozone on the activation of plants by triggering the initial defense system described earlier, which results in abrupt growth. For plant growth, an absorption of nutrients from the roots is quite important, as is a photosynthetic reaction in the leaves. For this reason, we focus on the activation of the underground roots of plants by feeding ozonated water under the surface. It is also noted that the concentration of ozone in water decays over time with a half decay time of about 30 min.

Our model plant system is komatsuna (Brassica rapa var. perviridis), Japanese mustard spinach, which is a leaf vegetable that may be eaten at any stage of its growth. Cultivation experiments were performed in a greenhouse of Tsubonuma Farm belonging to Miyagi University. Our plant cultivation system is shown in Fig. 1(a). Ozonated water was generated by introducing ambient air into an oxygen concentrator (FE-5, Inpal Co. Ltd.), employing a pressure swing adsorption (PSA) method and oxygen flow rate of 


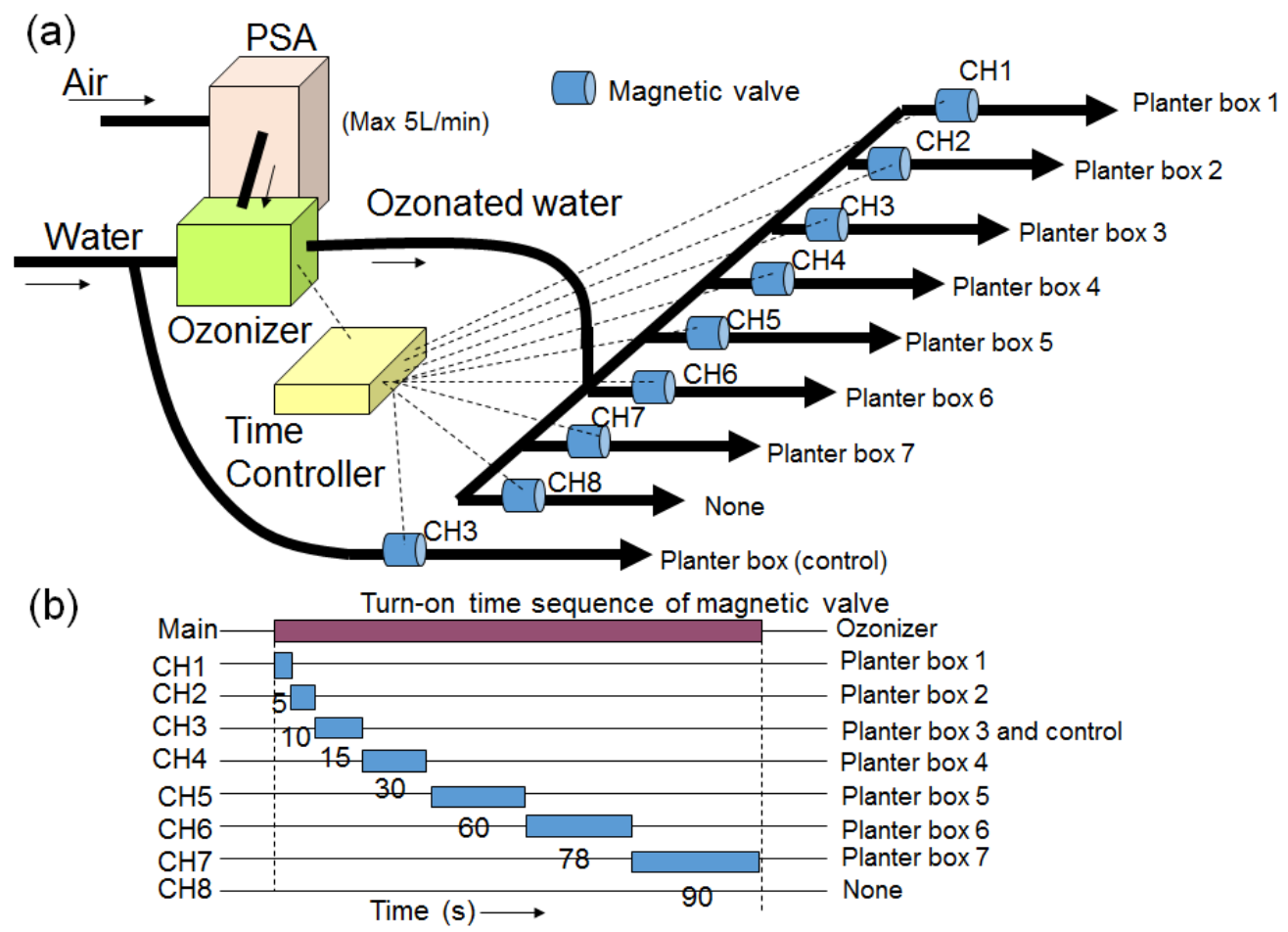

FIG. 1: (a) Plant cultivation system, including oxygen concentrator (PSA), ozone generator using barrier discharge, and time controller for switching magnetic valves. (b) Programmed time sequence for switching on and off the magnetic valves. Ozonated water is distributed automatically to each planter box

$5 \mathrm{~L} / \mathrm{min}$. The volume concentration of oxygen was more than $90 \%$. Then, oxygen gas was introduced into an ozonated water generator (Ozonated Water Generator, Inpal Co. Ltd.), in which ozone was produced efficiently by an atmospheric corona discharge in a narrow annular gap between outer grounded cylindrical pipe and inner coaxial rotating electrode with rotation speed of $1,380 \mathrm{turns} / \mathrm{min} .{ }^{19}$ In the corona discharge, the production of nitrogen oxides (NOX) was also reduced. Finally, ozone was mixed with flowing tap water by using a bubbling water jet method. The concentration of ozone diluted in the tap water was controlled by the discharge power and water flow rate. The flow rate of ozonated water was dependent on the input water pressure and the downstream pipe conductance. In our case, ozonated water of $1 \mathrm{ppm}$ with a flow rate of $0.6 \mathrm{~L} / \mathrm{min}$ was produced and employed throughout the experiment.

Here, we prepare eight plastic plant cultivation (planter) boxes that were $47.7 \mathrm{~cm}$ long, $32.6 \mathrm{~cm}$ wide, and $7.6 \mathrm{~cm}$ high, with several drain holes at the bottom. The ozonated water was distributed over time to those eight planter boxes by switching the magnetic valves on and off with an electric timer, Autorain Time Switch (FV811, SUNAO 


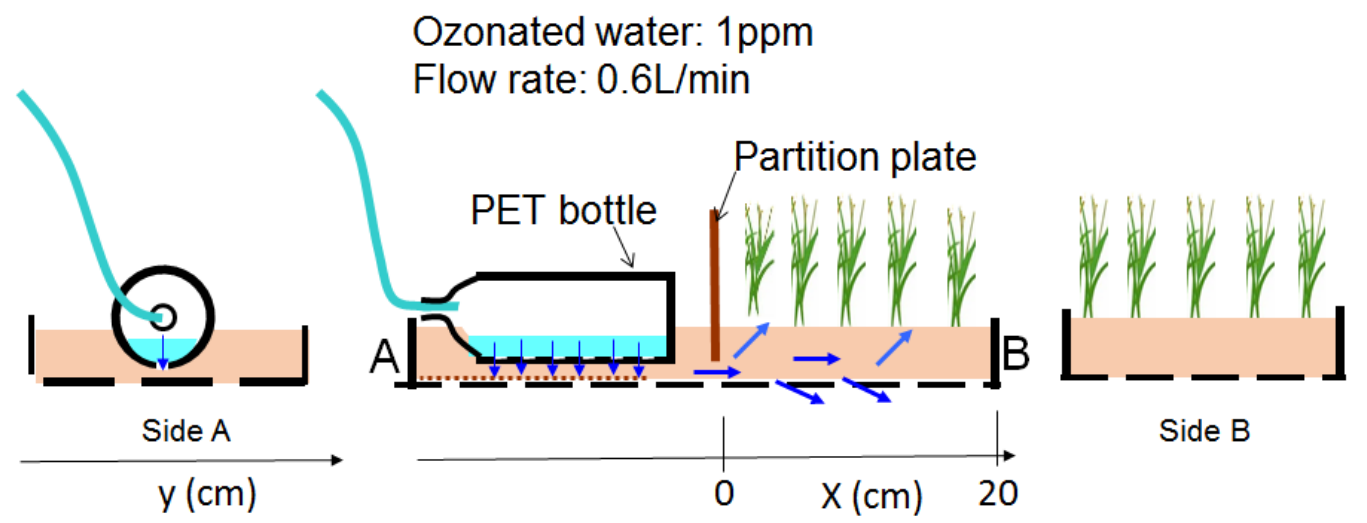

FIG. 2: Layout of planter box. The variable $x$ is the position in the cultivation area. Ozonated water is supplied from underground through a narrow channel beneath a partition plate inserted into the soil

Electric Co. Ltd.), with eight channels. The timing sequence of the valve switching is shown in Fig. 1(b). Here, one of the planter boxes was used for the control, to which tap water with the same flow rate as ozonated water was supplied by feeding the same electric switching signal as channel 3. The main switch of the timer was turned on and off automatically twice a day within 10 minutes between 9:00 am and 11:00 am every day except on rainy and cloudy days (34 days supplied), during cultivation from seeding to harvesting. Further, we prepared the ninth planter box (not shown in Fig.1), which was controlled by the same electric switching signal as channel 7, working every other day except rainy and cloudy days (18 days supplied).

The layout in the planter box is shown in Fig. 2. Cultivation soil (Sukoyaka, Yamagata Celltop, Co. Ltd.) was packed in the box with a depth of $5 \mathrm{~cm}$. The box is divided into two areas by a plastic partition plastic, inserted vertically $3 \mathrm{~cm}$ into the soil. One side is the cultivation area, and the other is the ozonated water feeding area. The end of a flexible water tube (outer diameter of $15 \mathrm{~mm}$ ), connected to the outlet of the magnetic valve, is inserted into an inlet of PET bottle (volume $2 \mathrm{~L}$ ) placed horizontally in ozonated water feeding area. Since the PET bottle was buried in the soil $2 \mathrm{~cm}$ below the surface, the water can leak into the soil directly through five holes, each $1 \mathrm{~cm}$ in diameter, opened in the vertical lower side of the PET bottle, and finally penetrate the cultivation area through a narrow channel below the partition panel placed between two areas. One hundred komatsuna seeds (cultivar 'Maruha,' Watanabe Seed Co. Ltd.) were sowed along the $x$ direction defined in Fig. 2, with five rows in the $y$ direction, perpendicular to the $x$ direction. After performing appropriate thinning, 25 samples of komatsuna ( 5 samples in the $x$ direction $\times 5$ samples in the $y$ direction) were harvested 49 days after sowing. To adjust the total amount of water added to the planters, tap water was sprinkled at 4:00 pm. 
(a)

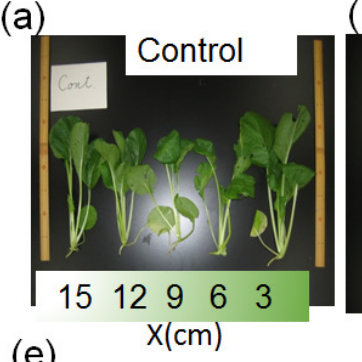

(e)

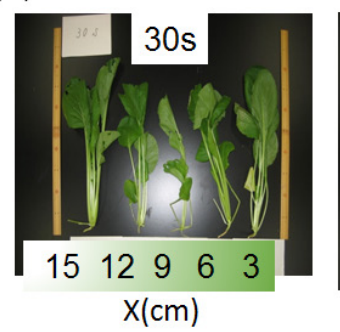

(b)

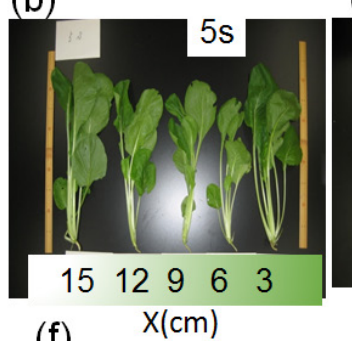

(f)

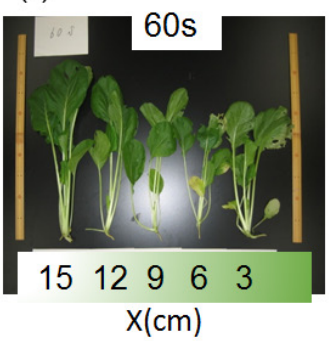

(c)

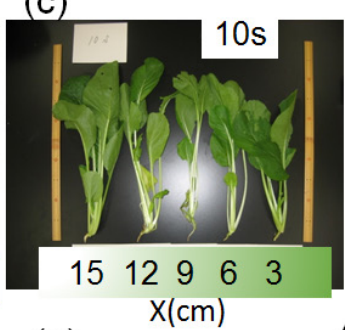

(g)

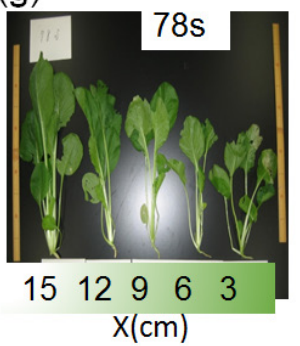

(d)

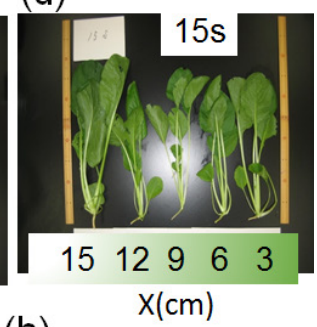

(h)

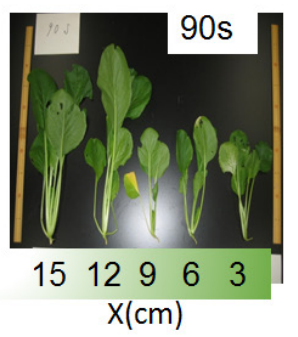

FIG. 3: Komatsuna sampled at $x=3 \mathrm{~cm}, 6 \mathrm{~cm}, 9 \mathrm{~cm}, 12 \mathrm{~cm}$, and $15 \mathrm{~cm}$, in case of (a) control (tap water feeding time $15 \mathrm{sec}$ ), and various ozonated water feeding times: (b) 5 $\mathrm{sec}$, (c) $10 \mathrm{sec}$, (d) $15 \mathrm{sec}$, (e) $30 \mathrm{sec,} \mathrm{(f)} 60 \mathrm{sec}$, (g) $78 \mathrm{sec}$, and (h) $90 \mathrm{sec}$. Dark yellow rulers of $50 \mathrm{~cm}$ long are placed on both sides

\section{EXPERIMENTAL RESULTS AND DISCUSSION}

Through the whole cultivation experiments, timer durations were fixed at $5 \mathrm{sec}, 10 \mathrm{sec}$, $15 \mathrm{sec}, 30 \mathrm{sec}, 60 \mathrm{sec}, 78 \mathrm{sec}$, and $90 \mathrm{sec}$ for channels 1, 2, 3, 4, 5, 6, and 7, respectively. Channel 8 was disconnected. Time duration of the control for supplying tap water was controlled by channel 3, as shown schematically in Fig. 1(b). Taking account of the flow rate of $1 \mathrm{ppm}$ ozonated water of $0.6 \mathrm{~L} / \mathrm{min}$, the amounts of ozonated water supplied at $x=0$ in the cases of $5 \mathrm{sec}, 10 \mathrm{sec}, 15 \mathrm{sec}, 30 \mathrm{sec}, 60 \mathrm{sec}, 78 \mathrm{sec}$, and $90 \mathrm{sec}$ are $50 \mathrm{~mL}$, $100 \mathrm{~mL}, 150 \mathrm{~mL}, 300 \mathrm{~mL}, 600 \mathrm{~mL}, 780 \mathrm{~mL}$, and $900 \mathrm{~mL}$, respectively.

Typical komatsuma samples in eight cases, harvested at $x=3 \mathrm{~cm}, 6 \mathrm{~cm}, 9 \mathrm{~cm}, 12$ $\mathrm{cm}$, and $15 \mathrm{~cm}$, are summarized in Fig. 3. Change of the size of control in the $\mathrm{x}$ direction was relatively small, but there appeared to be a mutual shading effect from the daylight, because the sizes at the both ends, $x=3 \mathrm{~cm}$ and $15 \mathrm{~cm}$, are a little bit larger than those in the middle at $x=6 \mathrm{~cm}, 9 \mathrm{~cm}$, and $12 \mathrm{~cm}$, as shown in Fig. 3(a). But, this effect was weakened in the other cases. Here, size distributions in the $x$ direction in the cases of 60 sec, $78 \mathrm{sec}$, and $90 \mathrm{sec}$ were quite remarkable. The sizes at $x=3 \mathrm{~cm}$ are much smaller than those at $x=15 \mathrm{~cm}$, and even smaller than that of control at $x=3 \mathrm{~cm}$. This might be due to a negative effect of ozone on the growth mechanism. Plant growth was considerably suppressed. Conversely, the sizes at $15 \mathrm{~cm}$ in the cases of $60 \mathrm{sec}, 78 \mathrm{sec}$, and 90 sec are much larger than that of the control at $x=15 \mathrm{~cm}$. This might be due to a positive 

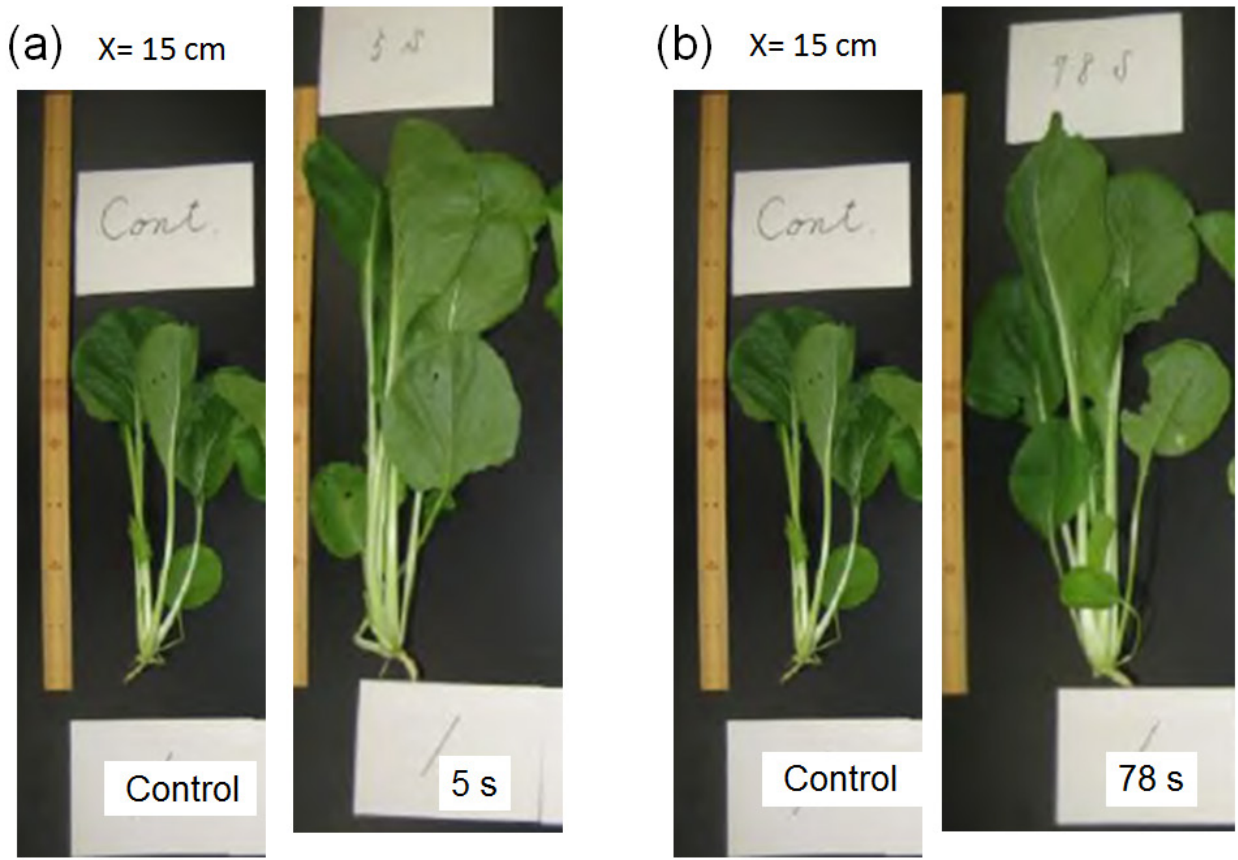

FIG. 4: Comparison of control with (a) $5 \mathrm{sec}$ feeding and (b) $78 \mathrm{sec}$ feeding. All samples are harvested at $x=15 \mathrm{~cm}$. A dark yellow ruler that is $50 \mathrm{~cm}$ long is placed on the side

effect of ozone on plant growth. Plant growth was considerably enhanced. The sizes of $5 \mathrm{sec}, 10 \mathrm{sec}$, and $15 \mathrm{sec}$ at $x=15 \mathrm{~cm}$ were also larger than that of control at $x=15 \mathrm{~cm}$.

Here, it should be noted that the positive effect of ozone comes from an initial quick response of the plant defense system resulting in secretion of plant hormone. Plants are internally activated by this response. On the other hand, a negative effect of ozone comes from a relatively slow response to the oxidative damage caused by hydroxyl radicals, $\mathrm{H}_{2} \mathrm{O}_{2}$, and superoxide oxidization. Our cultivation system employed intermittent irradiation of ozonated water. If the irradiation time is short, it is considered that the plant can avoid the slow negative effect and can maintain the initial positive effect during its growth.

In order to clarify these differences, sizes of komatsuna plants in the treatment groups of $5 \mathrm{sec}$ and $78 \mathrm{sec}$ at $x=15 \mathrm{~cm}$ are compared with that in the control at $x=15$ $\mathrm{cm}$, as shown in Figs. 4(a) and (b), respectively. As can be seen clearly, not only the sizes but also the number of leaves, number of stems, and width and length of leaves in the cases of $5 \mathrm{sec}$ and $78 \mathrm{sec}$ are much increased compared to those of control.

Fig. 5 shows the comparison of averaged weights at $x=3 \mathrm{~cm}$ and $15 \mathrm{~cm}$. Here, the averaged value was found by adding the weight of five komatsuna plants in the $y$ direction at the position $x$ and dividing the result by five. Broken horizontal lines show the values of the control at each position. At $x=3 \mathrm{~cm}$, only the weight in the case of $5 \mathrm{sec}$ 


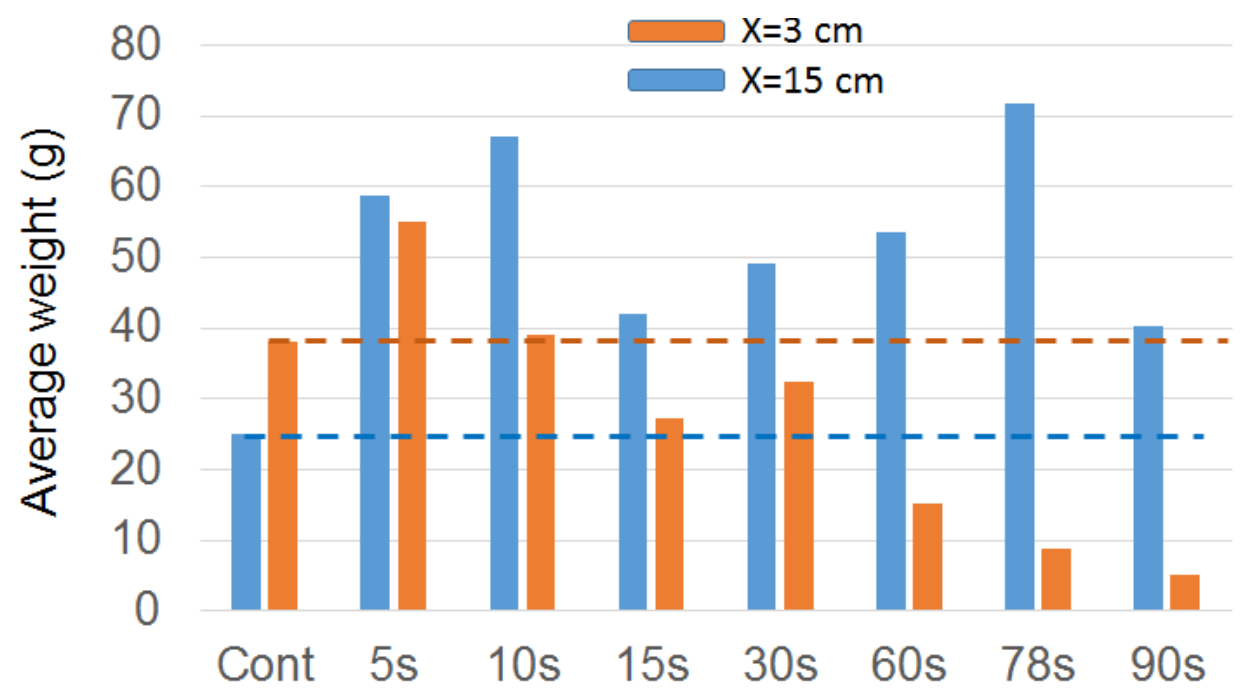

FIG. 5: Average weights of komatsuna sampled at $x=3 \mathrm{~cm}$ and $15 \mathrm{~cm}$ in eight cases. Dotted lines show the levels of the weight of control

surpassed the level of control. In all the other cases the weight was lower and below that of the control. This meant that near the ozonated water supply point $(x=0)$, the negative effect of ozone was dominated, except for the case of $5 \mathrm{sec}$. In other words, the amount of ozone delivered tot the 5-sec treatment group was optimal for triggering and maintaining the positive activity before suffering the negative oxidization effect of ozone. As a result, plant growth was promoted even at $x=3 \mathrm{~cm}$. On the other hand, it was quite remarkable that the weight of komatsuna at $x=15 \mathrm{~cm}$ was much larger than that of the control at $x=15 \mathrm{~cm}$. Because the amount of ozonated water arriving at $x=15 \mathrm{~cm}$ was reduced spatially and temporally by an absorption into the soil during its penetration, the negative effect of ozone was so weakened that the positive effect arising from the activities might result in the growth of the plants.

Variations of the averaged weight in all cases at different $x$ positions are shown in Fig. 6, including the data in the case of 90 -sec feeding twice a day every other day. As indicated by arrows in Fig. 6, there are two dominant peaks, especially for the samples at $x=15 \mathrm{~cm}$. One is a peak A in the case of 5-10 sec, and the other is peak B in the case of $78 \mathrm{sec}$, as shown by arrows. Averaged weight in the case of $5 \mathrm{sec}$ was $58.8 \mathrm{~g}$, which was 2.4 times the weight of the control, $(25.0 \mathrm{~g})$. On the other hand, averaged weight of the plants in the 78-sec treatment group was $71.8 \mathrm{~g}$, which was 2.9 times that of the control group. Because the amount of ozone supplied in the former peak, $50-100 \mathrm{~mL}$, was relatively small, it is possible that the damage suffered by irradiation of ozonated water could be repaired by the defense mechanism activating a positive effect to promote the plant growth. But, in the latter case, the amount of ozonated water supplied, $780 \mathrm{~mL}$, seemed to be too much. Therefore, komatsuna would suffer too much damage. In fact, 


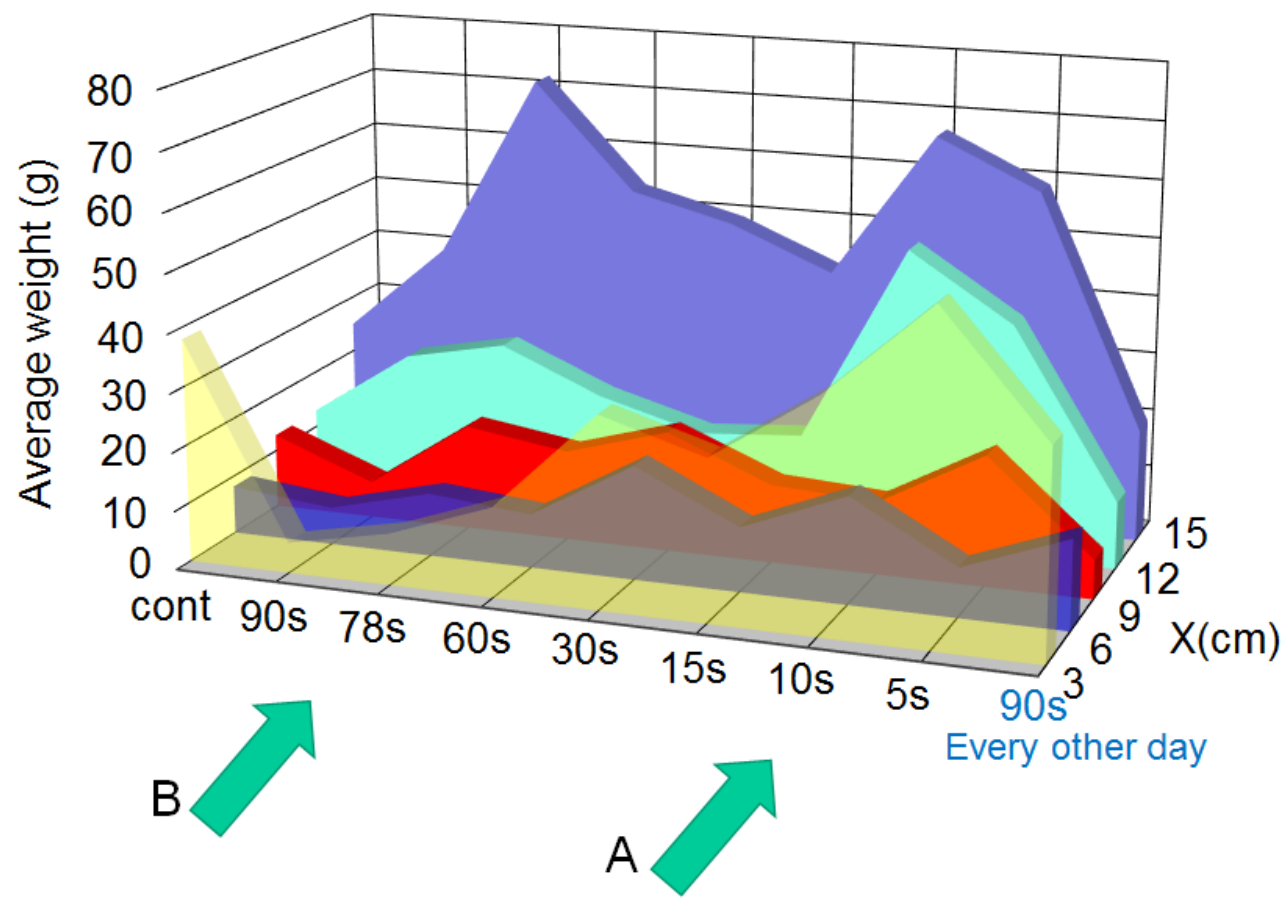

FIG. 6: Average weight distributions in all cases, including the case of 90-sec feeding every other day. Arrows A and B show two peaks in the cases of 5-10 sec and $78 \mathrm{sec}$, respectively

the growth of the plants at $3 \mathrm{~cm}$ was seriously suppressed by this negative effect. In spite of this fact, komatsuna grew 2.9 times as much as the control at $x=15 \mathrm{~cm}$. Therefore, it is considered that the growth mechanism in the case of $78 \mathrm{sec}$ at $x=15 \mathrm{~cm}$ is different from that in the case of $5-10 \mathrm{sec}$ at $x=15 \mathrm{~cm}$. Growth was observed not only in the weight but also the leaf width and length. Fig. 7 shows variations of averaged leaf width and length at $x=15 \mathrm{~cm}$. We can also find two peaks A and B in the cases of 5-10 sec and $78 \mathrm{sec}$, respectively.

In our experiment ozonated water was supplied intermittently in a very short time period twice a day every day except rainy and cloudy days, although the ozone concentration in water was rather strong at $1 \mathrm{ppm}$. Such intermittent irradiation of ozone to plants will be very important for a promotion of plant growth. Fig. 8 shows schematically an effect of intermittent ozone irradiation to plants G and D. As shown in Fig. 8(a), damage resulting from irradiation on time $\tau$ can be healed in the intermittent off-interval $T$ for plant $\mathrm{G}$, but plant $\mathrm{D}$ cannot recover from the damage within time $T$. Therefore, the ratio of irradiation time to feeding period, $\tau / T$, is an important factor as well as irradiation time $\tau$.

Furthermore, the total amount of ozone irradiation is also an important factor. From 


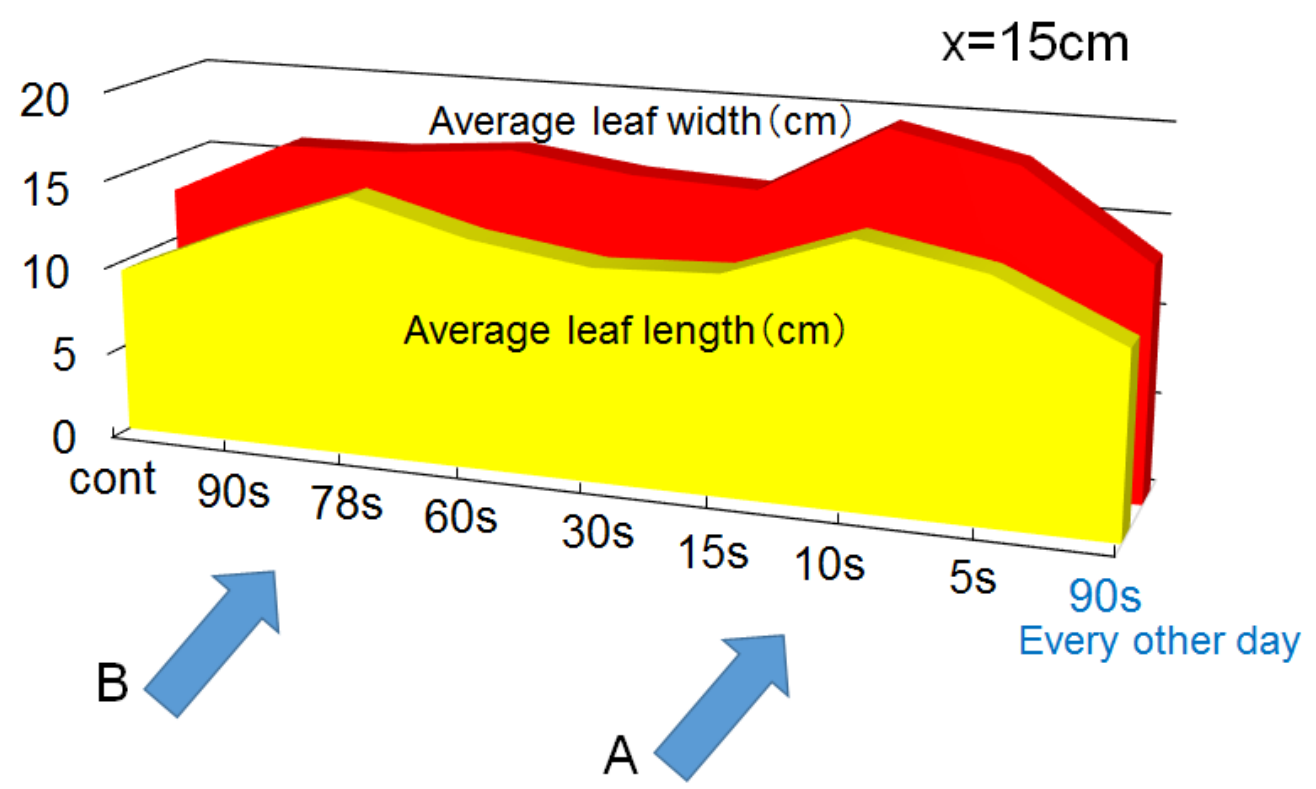

FIG. 7: Distributions of average leaf width and leaf length sampled at $x=15 \mathrm{~cm}$ in all cases, including the case of $90 \mathrm{sec}$ feeding every other day. Arrows A and B show two peaks in the cases of $5-10 \mathrm{sec}$ and $78 \mathrm{sec}$, respectively.

this experiment, there seem to exist two levels of defense mechanisms, as described previously, triggered at lower and higher thresholds. These correspond to the cases of 5-10 sec (A) and $78 \mathrm{sec}(\mathrm{B})$, respectively, as shown in Figs. 6 and 7. Recovery from the damage depends on the activity of the plant. Owing to the plant defense mechanism, activity of plant $\mathrm{G}$ will be enhanced with an increase in ozone irradiation, as shown in Fig. 8(b). However, plant $G$ cannot recover from the damage any more above the threshold and will die in the same way as plant D with a lower threshold. Therefore, there is an optimum amount of ozone irradiation that leads to recovery followed by growth promotion. In other words, an ideal intermittent irradiation of ozone promotes plant growth, as in the cases of 5-10 sec and $78 \mathrm{sec}$. This phenomenon will be useful in the agriculture industry in future.

\section{CONCLUSION}

The effect of ozone on the plant growth was examined by using ozonated water produced by an atmospheric barrier discharge. Ozonated water was supplied intermittently to the underground roots of komatsuna (Brassica rapa var. perviridis) by changing the feeding time twice a day every day for 49 days, except on rainy and cloudy days. There appeared to be a negative effect of ozone, which suppressed the plant growth near the feeding position $(x=0)$ of ozonated water. On the other hand, at $15 \mathrm{~cm}$ away from 
(a)

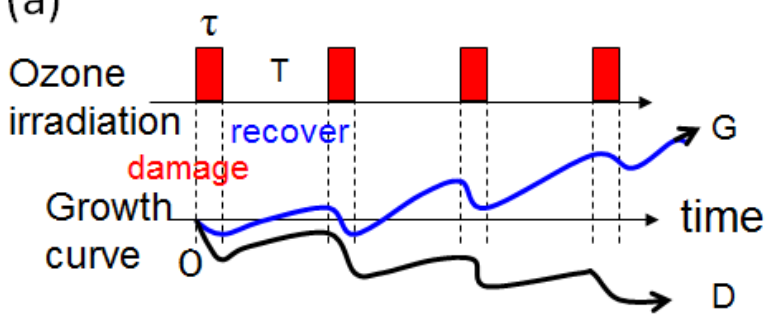

(b)

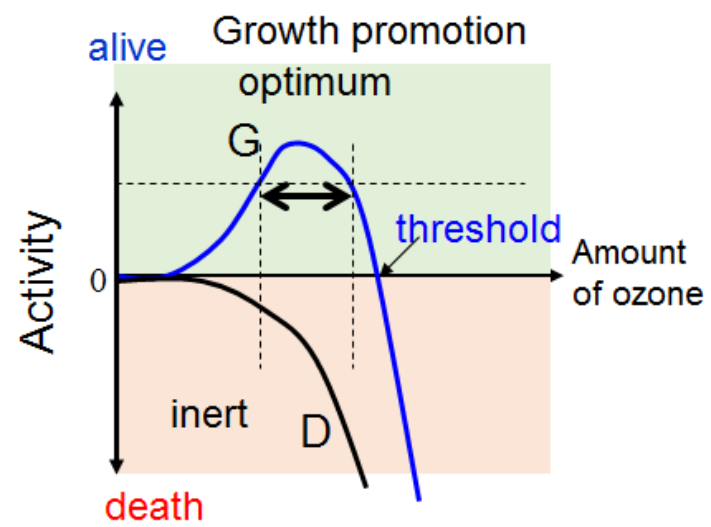

FIG. 8: A model of (a) growth curves and (b) activities of plants $G$ and $D$ under intermittent irradiation of ozone. In (a), damage suffered after irradiation at time $\mathrm{T}$ can be recovered in off-time interval $T$ for plant $G$, but not plant $D$. In (b), activities of plants $G$ and $D$ are shown as a function of irradiated amount of ozone, depending on $\mathrm{T} / T$. Plant $\mathrm{G}$ can recover within a threshold and can grow, but not above the threshold. Recovery is suppressed and activity is reduced for plant $\mathrm{D}$ with very low threshold

the feeding position, there were two peaks on the plant growth. Relative to the control group, the weight of komatsuna was increased by 2.4 times in the 5 -sec treatment group and by 2.9 times in the 78 -sec treatment group. The results revealed that an optimal amount of ozone supplied intermittently that will activate the plant growth.

\section{ACKNOWLEDGMENTS}

The authors would like to express their gratitude to Profs. Masahiro Nakamura (School of Food, Agricultural and Environmental Sciences, Miyagi University) and Minoru Sato (Graduate School of Agricultural Science, Tohoku University) for their interest and encouragement.

\section{REFERENCES}

1. Wilkinson S, Mills G, Illidge R, Davies WJ. How is ozone pollution reducing our food sup- 
ply? J Exp Bot. 2012;63:527-36.

2. Aben JMM, Jurkovicova MJ, Adema EH. Effects of low-level ozone exposure under ambient conditions on photosynthesis and stomatal control of Vicia faba L. Plant Cell Environ. 1990;13:463-69.

3. Heath RL, Taylor Jr GE. Physiological process and plant responses to ozone exposure. Ecol Stud. 1997:127:317-68.

4. Reid CD, Fiscus EL. Effects of elevated CO2and/or ozone on limitations to CO2 assimilation in soybean (Glycine max). J Exp Bot. 1998;18:885-95.

5. Heagle AS, Miller JE, Booker FL. Influence of ozone stress on soybean response to carbon dioxide enrichment: I. Foliar properties. Crop Sci. 1998;38:113-21.

6. Heagle AS, Miller JE, Pursley WA. Growth and yield responses of winter wheat to mixtures of ozone and carbon dioxide. Crop Sci. 2000;40:1656-64.

7. McKee IF, Mulholland BJ, Craigon J, Black CR, Long SP. Elevated concentrations of atmospheric $\mathrm{CO} 2$ protect against and compensate for $\mathrm{O} 3$ damage to photosynthetic tissues of field-grown wheat. New Phytol. 2000;146:427-35.

8. Pleijel H, Gelang J, Sild E, Danielsson H, Younis S, Karlsson PE, Wallin G, Skarby L, Sellden G. Effects of elevated carbon dioxide, ozone and water availability on spring wheat growth and yield. Physiol Plant. 2000;108:61-70.

9. Cardoso JV, Barnes J. Does nitrogen supply affect the response of wheat (Triticum aestivum cv. Hanno) to the combination of elevated CO2 and O3? J Exp Bot. 2001;52:1901-11.

10. Kangasjarvi J, Talvinen J, Utriainen M, Karjalainen R. Plant defence systems induced by ozone. Plant Cell Environ. 1994;17:783-94.

11. Vainonen U, Kangasjarvi J. Plant signalling in acute ozone exposure. Plant Cell Environ. 2015;38:240-52.

12. Betzelberger AM, Yendrek CR, Sun J, Leisner CP, Nelson RL, Ort DR, Ainsworth EA. Ozone exposure response for U.S. soybean cultivars: linear reductions in photosynthetic potential, biomass, and yield. Plant Physiol. 2012;160:1827-39.

13. Booker F, Muntifering R, McGrath M, Burkey K, Decoteau D, Fiscus E, Grantz D. The ozone component of global change: potential effects on agricultural and horticultural plant yield, product quality and interactions with invasive species. J Integr Plant Biol. 2009;51:337-51.

14. James DB, Jarmo KH, Ülo N. Plant volatiles in polluted atmospheres: stress responses and signal degradation. Plant Cell Environ. 2014;37:1892-904.

15. Mahalingam R, Shah N, Scrymgeour A, Fedoroff N. Temporal evolution of the Arabidopsis oxidative stress response. Plant Mol Biol. 2005:57:709-30.

16. Tosti N, Pasqualini S, Borgogni A, Ederli L, Falistocco E, Crispi S, Paolocci F. Gene expression profiles of O3-treated Arabidopsis plants. Plant Cell Environ. 2006;29:1686-702.

17. Puckette MC, Tang Y, Mahalingam R. Transcriptomic changes induced by acute ozone in resistant and sensitive Medicago truncatula accessions. BMC Plant Biol. 2008;8:46.

18. Blomster T, Salojärvi J, Sipari N, Brosché M, Ahlfors R, Keinänen M, Kangasjärvi J. Apoplastic reactive oxygen species transiently decrease auxin signaling and cause stress-induced morphogenic response in Arabidopsis. Plant Physiol. 2001;157:1866-83.

19. Schematic and performance of corona discharge apparatus with rotary electrode are described cessed in web pages titled "What is ozone?" and "Characteristics of ozone engine", respectively, in http://www.inpal.net/. (written in Japanese). 
